\title{
Comparative Analysis of The Characteristics of The Chinese gCJD Patients With E196A and E196K Mutation in PRNP
}

Qi Shi

Chinese Center for Disease Control and Prevention

Kang Xiao

Chinese Center for Disease Control and Prevention

Cao Chen

Chinese Center for Disease Control and Prevention

\section{Wei Zhou}

Chinese Center for Disease Control and Prevention

\section{Li-Ping Gao}

Chinese Center for Disease Control and Prevention

\section{Yue-Zhang Wu}

Chinese Center for Disease Control and Prevention

Yuan Wang

Chinese Center for Disease Control and Prevention

Chao Hu

Chinese Center for Disease Control and Prevention

Chen Gao

Chinese Center for Disease Control and Prevention

Xiao-Ping Dong ( $\square$ dongxp238@sina.com )

National Institute for Viral Disease Control and Prevention https://orcid.org/0000-0002-1566-8447

\section{Research Article}

Keywords: genetic Creutzfeldt-Jacob disease, E196A, E196K

Posted Date: April 5th, 2021

DOI: https://doi.org/10.21203/rs.3.rs-375212/v1

License: @ (i) This work is licensed under a Creative Commons Attribution 4.0 International License. Read Full License 


\section{Abstract}

Background: Genetic human prion diseases are a group of inherited encephalopathies caused by the different mutations in PrP-encoding gene PRNP. The clinical, neuropathological and laboratory features may differ largely according to the mutants at the different positions and with different amino acid. Here, we comparatively analyzed the features of 16 Chinese patients with E196A mutant and 5 patients with E196K mutant identified via Chinese National CJD Surveillance System (CNS-CJD). All genetic Creutzfeldt-Jacob disease (gCJD) with the mutations at codon 196 were Han-Chinese without blood kinship.

Methods: Neurological examination, EEG and MRI test, western blot, gene sequence and RT-QuIC.

Results: The onset-age of E196K gCJD cases (median of $61 \mathrm{y}$ ) was older than that of E196A ones (median of $67 \mathrm{y}$ ). Generally, these two subtypes of gCJD were more like sporadic CJD (sCJD) in clinical. The cases with E196A mutant showed more foremost symptoms, while those of E196K mutant restricted to dementia and mental problems. During the progression, more sCJD-associated symptoms and signs gradually appeared, but none of E196K cases showed cerebellum and visual disturbances. Typical PSWC on MRI was recorded in 20\% E196A cases but not in all E196K cases. SCJD-associated abnormalities on MRI, positive CSF 14-3-3 and increased CSF total tau were observed frequently, ranging from 2/3 to 4/5 cases without difference between E196A and E196K cases. Family history was not reported in all cases. Positive of CSF RT-QulC was detected in 37.5\% (6/16) E196A cases and 60\% (3/5) E196K cases. The duration of E196K cases (median of $4.5 \mathrm{~m}$, from 2 to $5 \mathrm{~m}$ ) were shorter than that of E196A cases (median of $6.5 \mathrm{~m}$, from 2 to $28 \mathrm{~m}$ ). Moreover, the female cases and the cases with young onset-age $(<60 \mathrm{y})$ of E196A cases displayed much longer survival times than the male patients and the cases with older onset-age $(>60 \mathrm{y})$.

Conclusion: E196A gCJD is now the $5^{\text {th }}$ most frequently observed genetic prion diseases in China. This is the largest comprehensive report of gCJD with the mutations at codon of 196 by now, which showing obvious diversity in clinical and laboratory tests between E196A and E196K mutants. Substitution of different amino acids at the same position induce the different clinical phenotype.

\section{Introduction}

Genetic human prion diseases, caused by the different mutations in PrP-encoding gene PRNP, accounts for approximate 10-15\% human prion diseases. Genetic human prion diseases have various medical terms based on their clinical and neuropathological phenotypes, i.e., genetic Creutzfeldt-Jacob disease (gCJD), Gerstmann-Straussler-Scheinker syndrome (GSS) and fatal familial insomnia (FFI), which are closely related with different mutations within PRNP [1, 2]. In the context of one same disease term, such as gCJD, the clinical, neuropathological and laboratory features differ largely according to the mutants at the different positions [3, 4]. Even at the same position, it contains different genotypes leading to the exchange of different amino acids (aa.) and subsequently displaying different phenotypical features, e.g., the mutants at codons 105, 188 and 196 [4].

Two different mutants at codon 196 have been reported to be related gCJD, E196A and E196K [4-8]. During the surveillance activity for CJD in China, 16 Chinese gCJD cases with E196A mutant and 5 cases with E196K were identified in the past ten years [9, 10]. Among them, the number of E196A gCJD was the 5th most frequently observed genetic prion diseases in China (Shi et al, unpublished data). In this study we comparatively analyzed the clinical and laboratory characteristics of the Chinese gCJD cases with E196A or E196K mutant. Both two types of gCJD revealed similar SCJD-like phenotype generally, meanwhile, showed diversities in some items of clinical and laboratory features.

\section{Materials And Methods Data collection}

As described previously $[10,11]$, the clinical data of the suspected CJD patients were collected by the neurologists in the local hospitals and the epidemiological data were collected by the staff from local provincial CDCs. The final diagnosis was given by the expert team consisting of neurologists, epidemiologists and laboratory staffs based on the diagnostic criteria for CJD recommended by WHO and that issued by Chinese National Health Commission 2017. The follow-up surveys for the patients were conducted by the staff of the center of CNS-CJD via telephone and/or WeChat.

\section{4-3-3 protein laboratory tests for CJD}

CSF samples were mixed with 5X loading buffer and boiled for $8 \mathrm{~min}$. Proteins were separated in 15\% SDS-polyacrylamide gel electrophoresis (PAGE) and transferred onto nitrocellulose (NC) membranes (Whatman, Pittsburgh, PA, USA) by the semi-dry method in transfer buffer and immunoblotted with anti-14-3-3 polyclonal antibody (1:1,000 dilution, Santa Cruz Biological). Reactive signals were visualized using an enhanced chemiluminescence (ECL) kit (AmershamPharmacia Biotech, Piscataway, NJ, USA).

Routine PRNP gene sequencing tests for CJD

Genomic DNA was extracted from peripheral blood leukocytes using a commercial kit (QIAGEN, Germany). One hundred nanograms of the extracted DNA were amplified by Polymerase Chain Reaction (PCR) using specific PRNP primers (forward primer: 5'-GGC AAA CCT TGG ATG CTG G-3' and reverse primer: 5'-CCC ACT ATC AGG AAG ATG AGG3') [10]

\section{ELISA for total tau in CSF}

The values of protein tau in CSF samples were quantitatively measured by a commercial ELISA kit (81572, Innotest hTau-Ag, Belgium). Briefly [12], 25 $\mu$ l of CSF sample was diluted with the buffer supplied by the manufacturer and added to wells of the antibody-coated plate in duplicate. The plate was incubated at

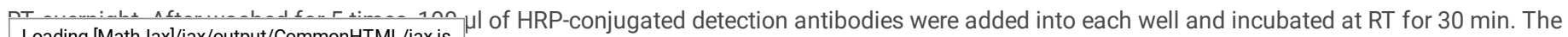
Loading [MathJax]/jax/output/CommonHTML/jax.js 
reactions were developed with $100 \mu$ substrate working solution for $30 \mathrm{~min}$ in dark. Absorbance at $450 \mathrm{~nm}$ was measured by a microplate reader (Perkin Elmer, USA) after terminating the reaction by addition of $2 \mathrm{M} \mathrm{H}_{2} \mathrm{SO}_{4}$. CSF tau concentrations were calculated based on a tau standard curve.

\section{RT-QulC assays}

RT-QulC assay was performed according to the working procedures described previously [13]. Briefly, each reaction contained $10 \mu \mathrm{g}$ of rHaPrP90-231, $1 \mathrm{X}$ PBS, $170 \mathrm{mM} \mathrm{NaCl}, 1 \mathrm{mM}$ EDTA, $0.01 \mathrm{mM}$ ThT, $0.001 \%$ SDS, together with $15 \mu \mathrm{l}$ CSF samples in a final volume of $100 \mu$ l. The assay was conducted in a black $96-$ well, optical-bottomed plate (Nunc, 265301) on a BMG FLUOstar plate reader (BMG LABTECH). The working conditions were: temperature, $55^{\circ} \mathrm{C}$; vibration speed, $700 \mathrm{rpm}$; vibration/incubation time, $60 / 60 \mathrm{sec}$; total reaction time, $60 \mathrm{~h}$. The ThT fluorescence value (excitation wavelength, $450 \mathrm{~nm}$; emission wavelength, $480 \mathrm{~nm}$ ) each reaction was automatically counted every $45 \mathrm{~min}$ and further presented as relative fluorescence units (rfu). Each sample was tested in quadruplicated simultaneously. The cutoff value was set as the mean value of the negative controls plus 10 times the standard deviation. A sample was considered to be positive when $\geq 2$ wells revealed positive reaction curves. $10^{-5}$ diluted the brain homogenate of the scrapie agent $263 \mathrm{~K}$-infected hamster was used as the positive control, while $10^{-5}$ diluted the brain homogenate of normal hamster as the negative control.

\section{Statistical assays}

The statistical analyses were performed using the SPSS 11.5 statistical software programme.

\section{Results}

\section{General information}

Since 2006, more than 200 genetic human prion disease cases have been identified and diagnosed via CNS-CJD, which consisted of 19 different subtypes of mutations in PRNP $[9,10]$. Among them, 16 cases were E196A gCJD and 5 cases were E196K gCJD. The first E196A and E196K gCJD cases were reported in 2011 and 2009, respectively (Fig. 1A). Afterwards, more cases of E196A gCJD were diagnosed, particularly since 2015 and peaked in 2017. E196K gCJD cases were markedly less frequent, reported one case in 2015, 2017, 2019 and 2020, respectively. The gender (M:F) distributions of E196A and E196K cases were 1:0.78 (9/7) and 1:1.5 (2/3). The onset ages of E196A cases varied from 43 to 76 years old $(\mathrm{y})$ with the median of $61 \mathrm{y}$, while that of E196K cases were from 61 to $77 \mathrm{y}$ with the median of $67 \mathrm{y}$. The peak of onset age of E196A patients was at the groups of 50-59y and 60-69y, which looked to be younger than that of E196K (Fig. 1B). Analysis of onset ages of the patients based on gender found that the median of E196A male patients were older than that of females (65 y vs 56 y), while the median of E196K male patients were younger than that of females (62.5 vs 73.5$)$. No significant geographic and occupational associated phenomenon was observed.

\section{Clinical features}

The clinical, genetic and laboratory data of 16 cases of E196A and 5 cases of E196K gCJD were summarized in Table 1. The intervals from onset to the diagnosed varied largely, ranging from 1 to 13 months $(m)$. Majority of the patients (18/21) were diagnosed within $6 \mathrm{~m}$ after onset, without notable difference between the groups of E196A and E196K. Most data of clinical manifestations, examinations and laboratory tests of those patients were mainly obtained during the periods of the hospitalizations referring to the center of CNS-CJD. Some information was collected via follow-up surveys after discharged. The patients with E196A mutant displayed 2 to 4 foremost symptoms (Table 2). Dementia (cognitive decline and memory loss) were complained in 68.8\% (11/16) cases, followed by mental problems (emotional lability, anxiety) in 62.5\% (10/14), extrapyramidal disfunction (unsteady gait, the drooling, the shaking of limbs) in 43.8\% (7/16), cerebellum disorder (ataxia, speech dysgraphia, dysmetria) in 43,8\% (7/16). Three patients described cortical blindness and one complained paresthesia. Slight difference in foremost symptoms was observed between gender and between young ( $<60 \mathrm{y})$ and senior ( $>60 \mathrm{y})$ patients, but without statistical significance. In contrast, five patients with E196K mutant appeared fewer initial disorders, limited on dementia (4/5) and mental problem $(2 / 5)$. Other symptoms were rarely recorded. 
Table 1

The main features of the Chinese E196A and E196K gCJD patients

\begin{tabular}{|c|c|c|c|c|c|c|c|c|c|c|c|c|c|c|c|}
\hline \multirow[t]{2}{*}{ Type } & \multirow[t]{2}{*}{ Case } & \multirow[t]{2}{*}{$\begin{array}{l}\text { Gender, } \\
\text { onset age, } \\
\text { province }\end{array}$} & \multirow[t]{2}{*}{ Initial } & \multirow[t]{2}{*}{ Dementia $^{1}$} & \multicolumn{4}{|c|}{$\begin{array}{l}\text { Other major } \\
\text { CJD-associated } \\
\text { problems }^{2}\end{array}$} & \multirow{2}{*}{$\begin{array}{l}\text { EEG } \\
\text { PSWCS }\end{array}$} & \multirow{2}{*}{$\begin{array}{l}\text { MRI } \\
\\
\text { Ribbon- } \\
\text { like } \\
\text { signal }\end{array}$} & \multicolumn{2}{|l|}{ CSF } & \multicolumn{3}{|c|}{ polymorp } \\
\hline & & & & & 1 & II & III & $\mathrm{Vl}$ & & & $\begin{array}{l}\text { High signals in } \\
\text { caudate/putamen }\end{array}$ & $\begin{array}{l}14- \\
3-3\end{array}$ & $\begin{array}{l}\text { Total } \\
\text { tau }\end{array}$ & $\begin{array}{l}\text { RT- } \\
\text { QulC }\end{array}$ & $\begin{array}{l}\text { Codor } \\
129\end{array}$ \\
\hline \multirow[t]{12}{*}{ E196A } & $\begin{array}{l}\text { Case } \\
1\end{array}$ & M, 76 y, Jilin & $\begin{array}{l}\text { mental } \\
\text { problem, } \\
\text { dementia }\end{array}$ & + & + & + & + & - & + & $\mathrm{NR}^{4}$ & - & + & + & + & $\mathrm{M} / \mathrm{M}$ \\
\hline & $\begin{array}{l}\text { Case } \\
2\end{array}$ & $\begin{array}{l}\text { F, } 54 \text { y, } \\
\text { Heilongjiang }\end{array}$ & $\begin{array}{l}\text { dementia, } \\
\text { cerebellum } \\
\text { disorder }\end{array}$ & + & - & + & + & - & $N C^{3}$ & NR & + & + & - & + & $\mathrm{M} / \mathrm{M}$ \\
\hline & $\begin{array}{l}\text { Case } \\
3\end{array}$ & $\begin{array}{l}\text { F, } 57 \text { y, } \\
\text { Zhejiang }\end{array}$ & $\begin{array}{l}\text { cerebellum } \\
\text { disorder }\end{array}$ & + & + & + & + & + & - & + & + & + & + & - & $\mathrm{M} / \mathrm{M}$ \\
\hline & $\begin{array}{l}\text { Case } \\
4\end{array}$ & $\begin{array}{l}\text { F, } 62 \mathrm{y}, \\
\text { Shanghai }\end{array}$ & $\begin{array}{l}\text { paresthesia, } \\
\text { cerebellum } \\
\text { disorder }\end{array}$ & + & + & + & + & + & NC & - & - & + & + & + & $\mathrm{M} / \mathrm{M}$ \\
\hline & $\begin{array}{l}\text { Case } \\
5\end{array}$ & $\begin{array}{l}\text { M, } 50 \text { y, } \\
\text { Guangdong }\end{array}$ & $\begin{array}{l}\text { dementia, } \\
\text { mental } \\
\text { problem, } \\
\text { extramidal } \\
\text { disfunction }\end{array}$ & + & + & - & + & + & - & - & + & + & + & - & $\mathrm{M} / \mathrm{M}$ \\
\hline & $\begin{array}{l}\text { Case } \\
6\end{array}$ & $\begin{array}{l}\text { M, } 68 \text { y, } \\
\text { Guangdong }\end{array}$ & $\begin{array}{l}\text { cerebellum } \\
\text { disorder, } \\
\text { alalia }\end{array}$ & + & + & + & + & - & - & + & + & + & + & - & $\mathrm{M} / \mathrm{M}$ \\
\hline & $\begin{array}{l}\text { Case } \\
7\end{array}$ & M, $72 y$, Jilin & $\begin{array}{l}\text { dementia, } \\
\text { mental } \\
\text { problem, } \\
\text { extramidal } \\
\text { disfunction }\end{array}$ & + & + & - & + & + & NC & - & - & - & + & + & $\mathrm{M} / \mathrm{M}$ \\
\hline & $\begin{array}{l}\text { Case } \\
8\end{array}$ & $\begin{array}{l}\text { M, } 62 \mathrm{y}, \\
\text { Chongqing }\end{array}$ & $\begin{array}{l}\text { dementia, } \\
\text { cerebellum } \\
\text { disorder, } \\
\text { extramidal } \\
\text { disfunction }\end{array}$ & + & + & + & + & - & + & + & - & + & + & - & $\mathrm{M} / \mathrm{M}$ \\
\hline & $\begin{array}{l}\text { Case } \\
9\end{array}$ & $\begin{array}{l}\text { M, } 60 \text { y, } \\
\text { Guangdong }\end{array}$ & $\begin{array}{l}\text { dementia, } \\
\text { mental } \\
\text { problem }\end{array}$ & + & - & - & - & - & - & + & + & - & - & - & $\mathrm{M} / \mathrm{M}$ \\
\hline & $\begin{array}{l}\text { Case } \\
10\end{array}$ & $\begin{array}{l}\text { M, } 69 \mathrm{y} \\
\text { Chongqing }\end{array}$ & $\begin{array}{l}\text { dementia, } \\
\text { cerebellum } \\
\text { disorder, } \\
\text { extramidal } \\
\text { disfunction, } \\
\text { mental } \\
\text { problem }\end{array}$ & + & + & + & + & + & - & + & - & - & + & - & $\mathrm{M} / \mathrm{M}$ \\
\hline & $\begin{array}{l}\text { Case } \\
11\end{array}$ & $\begin{array}{l}\text { F, } 53 \text { y, } \\
\text { Yunnan }\end{array}$ & $\begin{array}{l}\text { dementia, } \\
\text { mental } \\
\text { problem, } \\
\text { extramidal } \\
\text { disfunction }\end{array}$ & + & + & + & + & + & + & + & - & + & $N^{5}$ & - & $\mathrm{M} / \mathrm{M}$ \\
\hline & $\begin{array}{l}\text { Case } \\
12\end{array}$ & $\begin{array}{l}F, 74 y, \\
\text { Fujian }\end{array}$ & $\begin{array}{l}\text { dementia, } \\
\text { mental } \\
\text { problem, } \\
\text { extramidal } \\
\text { disfunction }\end{array}$ & + & - & - & + & + & - & + & - & + & ND & + & $\mathrm{M} / \mathrm{M}$ \\
\hline
\end{tabular}

${ }^{1}$ Rapid progressive dementia

${ }^{2}$ I: myoclonic movement; II: Cerebellum and visual disturbances; III: Pyramidal or extramidal disfunction; Vl: Akinetic mutism

${ }^{3}$ uncertain

${ }^{4}$ not recorded

Loading [MathJax]/jax/output/CommonHTML/jax.js 


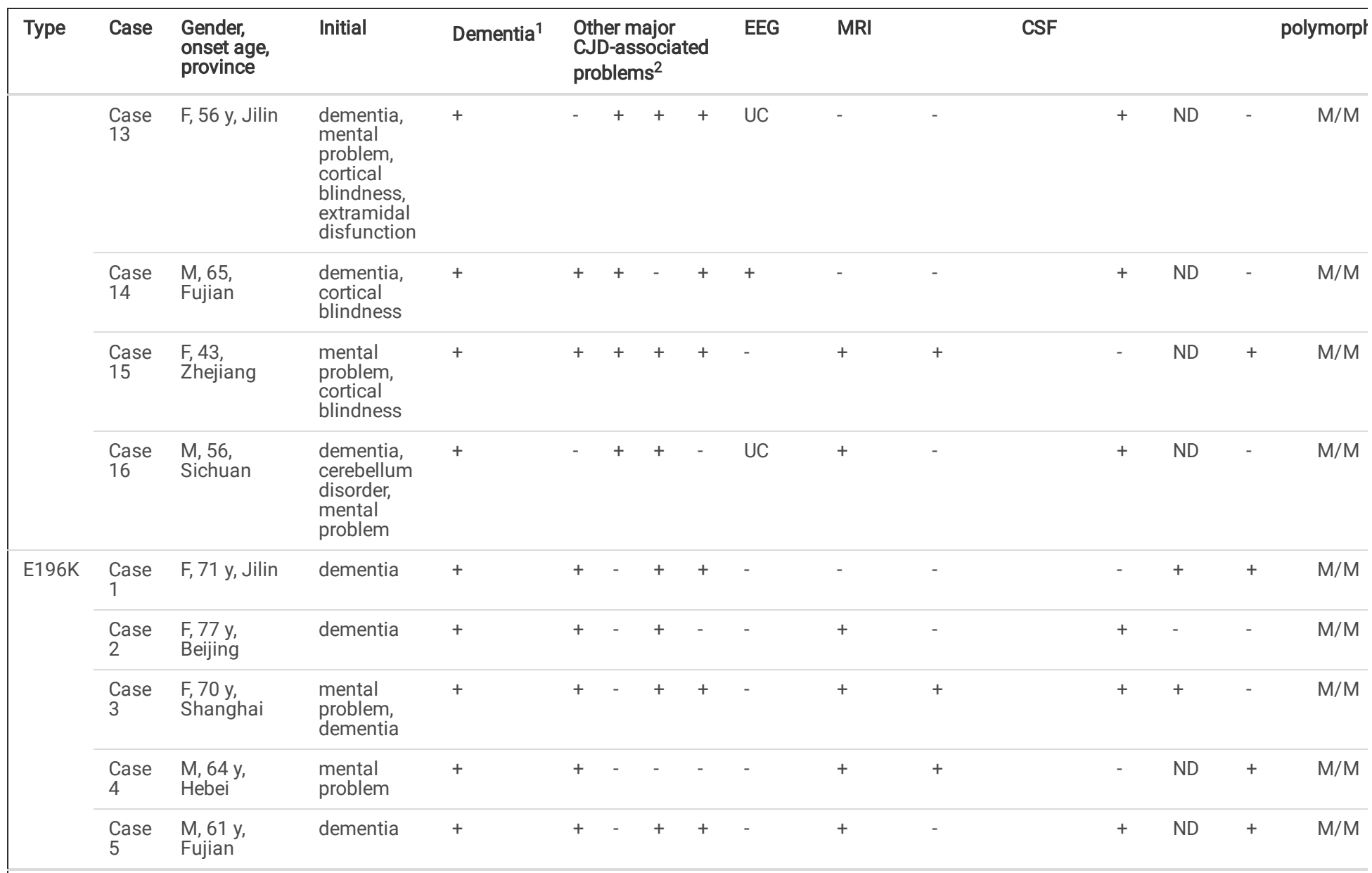

${ }^{1}$ Rapid progressive dementia

2 I: myoclonic movement; II: Cerebellum and visual disturbances; III: Pyramidal or extramidal disfunction; VI: Akinetic mutism

${ }^{3}$ uncertain

${ }^{4}$ not recorded

${ }^{5}$ not done

Table 2

The foremost symptoms of the gCJD patients with E196A or E196K mutation

\begin{tabular}{|c|c|c|c|c|c|c|c|c|}
\hline \multirow[t]{2}{*}{ Foremost symptoms } & \multicolumn{5}{|l|}{ E196A } & \multicolumn{3}{|l|}{ E196K } \\
\hline & Total $(n=16)$ & $M(n=9)$ & $F(n=7)$ & $<60$ y $(n=7)$ & $>60(n=9)$ & Total $(n=5)$ & $M(n=2)$ & $F(n=3)$ \\
\hline Dementia & $11(68.8 \%)$ & $7(77.8 \%)$ & $4(57.1 \%)$ & $5(71.4 \%)$ & $6(66.7 \%)$ & $4(80.0 \%)$ & $1(50 \%)$ & $3(100.0 \%)$ \\
\hline Mental problem & $10(62.5 \%)$ & $6(66.7 \%)$ & $4(57.1 \%)$ & $5(71.4 \%)$ & $5(55.6 \%)$ & $2(40.0 \%)$ & $1(50 \%)$ & $1(33.3 \%)$ \\
\hline Extrapyramidal disfunction & $7(43.8 \%)$ & $4(44.4 \%)$ & $3(42.9 \%)$ & $3(42.9 \%)$ & $4(44.4 \%)$ & 0 & 0 & 0 \\
\hline Cerebellum disorder & $7(43.8 \%)$ & $4(44.4 \%)$ & $3(42.9 \%)$ & $3(42.9 \%)$ & $3(33.3 \%)$ & 0 & 0 & 0 \\
\hline Cortical blindness & $3(18.8 \%)$ & $1(11.1 \%)$ & $2(28.6 \%)$ & $2(28.6 \%)$ & $1(11.1 \%)$ & 0 & 0 & 0 \\
\hline
\end{tabular}

Along with the progression, rapid progressive dementia was reported in all patients regardless E196A or E196K. Other sCJD-associated symptoms and signs were also noticed gradually. In the group of E196A mutant, 5 patients were recorded having 4 major sCJD-associated symptoms, 7 cases having 3 symptoms, 3 cases having 2 symptoms. Only one case (Case 9) did not appear those 4 major symptoms but with clear mental problems (Table 1). The detecting rates of myoclonus, cerebellum and visual disorders, pyramidal and extrapyramidal symptoms, mutism were 68.8\% (11/16), 81.3 (13/16), 87.5\% (14/16) and 62.5\% (10/16), respectively (Fig. 2A). In the group of E196K mutant, all five patients showed myoclonic movement while none of them reported cerebellum and visual disorders. Four cases displayed pyramidal and extrapyramidal symptoms, and two had mutism (Table 1 and Fig. 2B). These data highlight that the clinical features of those Chinese E196A and E196K gCJD are not exactly same.

\section{EEG and MRI features}


All patients received EEG and MRI examinations at least one time. In the group of E196A mutant, 4 patients recorded typical periodic sharp wave complexes (PSWCs) on EEG, 7 showed different abnormalities but without PSWCs, and other 5 cases were PSWCs uncertain (Table 1, Fig. 3A). The positive rate of definite PSWC on EEG in E196A cases was 25\%. In the group of E196K, none of those 5 patients showed typical PSWCs (Fig. 3A). The sCJD-associated MRI abnormalities (ribbon-like signal in DWI and/or high signals in caudate/putamen) were observed in $68.8 \%(11 / 16)$ of E196A cases and $80 \%$ (4/5) of E196K cases (Fig. 3B). Ribbon-like signals ( 9 out of 14 cases with El96A and 4 with E196K) were more frequently detected than high signals in caudate/putamen (6 cases with E196A and 2 with E196K) (Table 1).

\section{PRNP gene sequencing}

Containing the mutation at codon 196 of those patients in one PRNPallele was verified by direct sequencing of the PCR products, which was routinely repeated at least two times with newly extracted DNAs. 16 suspected CJD cases contained a missense mutation at codon 196 of $P R N P$ gene, leading to a substitution of Glutamic acid (Glu) by Alanine (Ala), while 5 cases had a mutation causing substitution of Glutamic acid (Glu) by Lysine (Lys). No additional nucleotide exchanges were found in other regions of the PRNP sequences of those cases. All patients were methionine homozygosity at codon 129 (M129M). 15 out of 16 E196A cases were glutamic acid homozygosity at codon 219 (E219E) and one case (Case 12) was glutamic acid/lysine heterozygosity (E219K). All of 5 E196K cases had the sequencing data of codon 219, revealing E219E.

\section{CSF protein 14-3-3 and tau}

Lumber puncture was conducted for all patients here. Routine items (cells, proteins, glucose, electrolytes, etc.) in CSF biochemistry were all in the normal ranges. Western blots for CSF 14-3-3 were positive in 75\% (12/16) of E196A cases and 60\% (3/5) of E196K cases (Fig. 3C). The total tau levels in CSF samples from 10 cases with E196A and 3 case with E196K (Table 1) were measured with a commercial ELISA kit and the tau level higher than 1400 pg/ml was considered as positive based on previous studies [12,14]. CSF total tau positive were identified in 8 (out of 10) cases with E196A mutant and 2 (out of 3) cases with E196K mutant (Fig. 3D).

\section{RT-QulC features}

All cases with E196A and E196K mutant in this study were subjected into RT-QulC tests with $15 \mu \mathrm{l} \mathrm{CSF} \mathrm{sample} \mathrm{each,} \mathrm{using} \mathrm{a} \mathrm{recombinant} \mathrm{truncated} \mathrm{hamster}$ PrP protein aa 90-231 (rHaPrP90-231) as the substrate. Under our experimental condition, 37.5\% (6/16) of E196A gCJD cases and 60\% (3/5) E196K gCJD cases were positive in CSF RT-QuIC (Fig. 4, Table 1). There was no marked difference in the positive conversion time and the peak of the reactive curves in RTQulC between those two groups.

\section{Survival time}

By the end of July 2020, 12 cases with E196A died, 3 cases are alive and 1 was lost, while 4 cases with E196K died and 1 was lost (Table 1). As shown in Fig. 5A, the durations of the patients of E196A gCJD varied largely from 2 to 28 months, with the median of survival of $6.5 \mathrm{~m}$. Half of the dead cases died within $5 \mathrm{~m}$ after onset. In contrast, all 4 dead cases of E196K gCJD died within 5 months, with the median of $4.5 \mathrm{~m}$ (ranging from 2 to $5 \mathrm{~m}$ ) after onset. Analysis of the medians of survival between two types of gCJD revealed statistical difference $(P=0.018)$. Three E196A cases were alive with the clinical durations of 36, 20 and 3 months already, respectively (Table 1). Further, the survival times of 12 dead cases with E196K were analyzed based on the gender and the onset-age. Male patients $(n=6)$ showed much shorter survival times (median: 4 m, ranging 2 to 10 m) than the females $(n=6)$ (median: 15 m, ranging from 4 to $28 \mathrm{~m}$ ) (Fig. $5 B$ ), with significant difference $(P=0.009)$. The senior cases ( $\geq 60 y, n=7$ ) had much shorter survival times (median: $4 \mathrm{~m}$, ranging from 2 to $8 \mathrm{~m}$ ) than the younger ones $(<60 \mathrm{y}, \mathrm{n}=5)$ (Fig. $5 \mathrm{C})$, showing significant difference $(P=0.001)$.

\section{Discussion}

Human genetic prion diseases display huge diversity in clinical and laboratory. In the study, we have comparatively analyzed the features of Chinese E196A and E196K gCJD patients from the points of demography, clinical, EEG and MRI, CSF laboratory tests. Unfortunately, we do not have any brain specimen, either postmortem or biopsy, from the patients here, so that the neuropathological and PrPSc features of Chinese E196A and E196K gCJD patients still remain unclear. Generally, the clinical features of both E196A and E196K gCJD cases similar to SCJD, e.g., displaying rapid progressive dementia and other major manifestations, high positive rates of MRI abnormalities, CSF 14-3-3 and total tau. However, the cases with E196A and E196K here also show notable diversity in some items. The onset ages of E196A patients are similar to Chinese SCJD patients [10], but those of five E196K cases are relatively older. The foremost symptoms of E196A cases are more diversity but E196K cases are confined to dementia and mental problems. Cerebellum and visual disturbances are frequent in E196A cases, but not noticed in E196K patients. PSWCs on EEG is not observable in all E196K cases but is recordable in a small portion of E196A cases. Additionally, E196K cases seems to have more ratios of positive CSF RT-QulC than E196A cases. E196K gCJD has been reported in many European countries. Unlike the five Chinese cases, the phenotypes of European patients are more diverse, such as cerebellum problems and PSWC on EEG, which were observed in a portion of gCJD patients with E196K [15-18]. We have to say that majority data and specimens of the patients here were collected and tested during their last hospitalization that we cannot exclude the possibility to appear other neurological signs afterwards. As the number of E196K cases in this study is small, it still needs more cases in order to define the difference between Chinese and European E196K gCJD cases.

Four dead cases with E196K display much shorter clinical duration than 12 dead E196A cases in this study. However, the survival times of the published Caucasian E196K gCJD differ considerably, varying from 2 to $18 \mathrm{~m}$ with the median of $7.5 \mathrm{~m}$ [6, 16-19]. Due to the limited numbers of Chinese E196K gCJD, it is still too early to get the conclusion for such difference between Chinese and Caucasian patients. The cases with E196A here show wide range of durations like sCJD cases in China $[10,20]$. Unlike sCJD, the female patients and senior patients of Chinese E196A gCJD show much long durations than male and 
young patients in general. The exact reason for those phenomena remains unknown. One male case with onset age of $60 \mathrm{y}$ (Case 9 ) is still alive $36 \mathrm{~m}$ postonset. The exact feature of survival times in E196K gCJD still need more cases.

Our data here show about three times more E196A cases than E196K cases in the past 10 years. As we do not know the frequency of those two genotypes in general Han-Chinese, such diversity in case numbers reflects only the difference in disease occurrence and identification. None of the family members from those 21 patients undertake the assays of PRNP sequencing. Thereby, we are also unable to speculate the exact penetrance of those two mutants. The penetrance of the mutations in $P R N P$ has been evaluated by several studies $[4,21,22]$. However, the exact pathogenicity of many rare mutants is still poorly understood probably as very limited case numbers. Penetrance of the PRNP mutants is associated with the family history. Low-penetrance mutants seem to have low positive rates of family history [21]. None of the cases in this study record family history, which might highlight low penetrance of E196A and E196K mutants. Penetrance of the PRNP mutants is also influenced by the ages. One example is Sephardic E200K mutation carriers, among them penetrance is $70 \%$ at age $70 \mathrm{y}$ and close to $100 \%$ at age $85 \mathrm{y}$ [23]. Screening PRNP mutation in the senior patients with neurological problems will benefit to identify untypical gCJD. On the other hand, relatively late onset-age, such as Chinese E196K gCJD cases with short duration in this study, may also increase the probability of case loss because of died or misdiagnosis of other diseases.

E196K gCJD was firstly reported in 2000 described six German patients [16], while E196A gCJD was reported late in China [24]. Based the literatures, dozens of E196K gCJD cases have been described in European countries, such as Germany, Italy, France, UK [2, 4, 6, 16-18, 25]. In contrast, E196K mutant is rarely reported in East Asian besides of Chinese cases described previously [8] and in this study. On the other hand, E196A mutant seems to be confined to Chinese and to be extremely rare in other countries and ethnics by now. It shows again the difference in PRNP mutants and polymorphisms between ethnics. Nevertheless, E196A gCJD becomes the second Han-Chinese predominate subtype after T188K gCJD [9, 10, 26], which differ not only with Caucasian but also with other East Asian, e.g., Japanese and Korean.

\section{Conclusion}

E196A gCJD is now the 5th most frequently observed genetic prion diseases in China. This is the largest comprehensive report of gCJD with the mutations at codon of 196 by now, which showing obvious diversity in clinical and laboratory tests between E196A and E196K mutants. Substitution of different amino acids at the same position induce the different clinical phenotype.

\section{Declarations}

\section{Ethical Approval and Consent to participate}

Usage of the surveillance data of the patients with E196A and E196K gCJD in Chinese National CJD Surveillance System (CNS-CJD) has been approved by the Research Ethics Committee of National Institute for Viral Disease Control and Prevention, China CDC (CCDC).

\section{Consent for publication}

The written informed consent of each suspected case has been asked and signed by the family member or the relative of the patient according to the requirement of CJD surveillance. And all methods were carried out in accordance with relevant guidelines and regulations.

\section{Availability of data and materials}

All data generated or analysed during this study are included in this published article.

\section{Competing interests}

The authors declare that they have no competing interests

\section{Funding}

This work was supported by Chinese National Natural Science Foundation Grants (81630062), National Key R\&D Program of China (2018ZX10711001, 2017YFC1200500), and Grant (2019SKLID501§2019SKLID603§2019SKLID307) from the State Key Laboratory for Infectious Disease Prevention and Control, China CDC.

\section{Authors' contributions}

Q.S. contributed to study design, performed assays and data analysis, and prepared the manuscript. K.X., W.Z.,C.G. and Y.Z.W. assisted with the assays of Western Blot analysis. L.P.G.,Y.W., C.H. and C.C. assisted with the animal tests. X.P.D. corresponding authors, contributed to design, study concept, and manuscript preparation.

\section{Acknowledgements}

We thanked the colleagues from CDC in all provinces and cities.

\section{Authors' information}


Corresponding Authors

Qi Shi - State Key Laboratory for Infectious Disease Prevention and Control, Collaborative Innovation Center for Diagnosis and Treatment of Infectious Diseases (Zhejiang University),

National Institute for Viral Disease Control and Prevention, Chinese Center for Disease Control and Prevention, Beijing 102206, China; China Academy of Chinese Medical Sciences,

Beijing 100700, China; Email: shiqi76@126.com

Xiao-Ping Dong - State Key Laboratory for Infectious Disease Prevention and Control, Collaborative Innovation Center for Diagnosis and Treatment of Infectious Diseases (Zhejiang

University), National Institute for Viral Disease Control and Prevention, Chinese Center for Disease Control and Prevention, Beijing 102206, China; Center for Global Public Health, Chinese Center for Disease Control and Prevention, Beijing 102206, China; Center for Biosafety Mega-Science, Chinese

Academy of Sciences, Wuhan 430071, China; China Academy of Chinese Medical Sciences, Beijing 100700, China; orcid.org/0000-0002-1566-8447; Email: dongxp238@sina.com

Author

Kang Xiao - State Key Laboratory for Infectious Disease Prevention and Control, Collaborative Innovation Center for Diagnosis and Treatment of Infectious Diseases (Zhejiang University), National Institute for Viral Disease Control and Prevention, Chinese Center for Disease Control and Prevention, Beijing 102206, China

Cao Chen- State Key Laboratory for Infectious Disease Prevention and Control, Collaborative Innovation Center for Diagnosis and Treatment of Infectious Diseases (Zhejiang University), National Institute for Viral Disease Control and Prevention, Chinese Center for Disease Control and Prevention, Beijing 102206, China

Wei Zhou- State Key Laboratory for Infectious Disease Prevention and Control, Collaborative Innovation Center for Diagnosis and Treatment of Infectious Diseases (Zhejiang University), National Institute for Viral Disease Control and Prevention, Chinese Center for Disease Control and Prevention, Beijing 102206, China

Li-Ping Gao - State Key Laboratory for Infectious Disease Prevention and Control, Collaborative Innovation Center for Diagnosis and Treatment of Infectious Diseases (Zhejiang University), National Institute for Viral Disease Control and Prevention, Chinese Center for Disease Control and Prevention, Beijing 102206, China

Yue-Zhang Wu - State Key Laboratory for Infectious Disease Prevention and Control, Collaborative Innovation Center for Diagnosis and Treatment of Infectious Diseases (Zhejiang University), National Institute for Viral Disease Control and Prevention, Chinese Center for Disease Control and Prevention, Beijing 102206, China

Yuan Wang - State Key Laboratory for Infectious Disease Prevention and Control, Collaborative Innovation Center for Diagnosis and Treatment of Infectious Diseases (Zhejiang

University), National Institute for Viral Disease Control and Prevention, Chinese Center for Disease Control and Prevention, Beijing 102206, China

Chao Hu- State Key Laboratory for Infectious Disease Prevention and Control, Collaborative Innovation Center for Diagnosis and Treatment of Infectious Diseases (Zhejiang University), National Institute for Viral Disease Control and Prevention, Chinese Center for Disease Control and Prevention, Beijing 102206, China

Chen Gao- State Key Laboratory for Infectious Disease Prevention and Control, Collaborative Innovation Center for Diagnosis and Treatment of Infectious Diseases (Zhejiang University), National Institute for Viral Disease Control and Prevention, Chinese Center for Disease Control and Prevention, Beijing 102206, China

\section{References}

1. Chen C, Dong XP. Epidemiological characteristics of human prion diseases. Infect Dis Poverty. 2016;5(1):47.

2. Kovacs GG, et al. Genetic prion disease: the EUROCJD experience. Hum Genet. 2005;118(2):166-74.

3. Baldwin KJ, Correll CM. Prion Disease Semin Neurol. 2019;39(4):428-39.

4. Kim MO, et al., Genetic PrP Prion Diseases. Cold Spring Harb Perspect Biol, 2018. 10(5).

5. Jeong BH, Kim YS. Genetic studies in human prion diseases. J Korean Med Sci. 2014;29(5):623-32.

6. Schelzke G, et al., Genetic prion disease with codon 196 PRNP mutation: clinical and pathological findings. Neurobiol Aging, 2011. $32(4)$ : p. 756 e1-9.

7. Shi Q, et al. Rare E196A mutation in PRNP gene of 3 Chinese patients with Creutzfeldt-Jacob disease. Prion. 2016;10(4):331-7.

8. Shi Q, et al. A Chinese Creutzfeldt-Jakob disease patient with E196K mutation in PRNP. Prion. 2011;5(2):117-20.

9. Shi Q, et al. The Features of Genetic Prion Diseases Based on Chinese Surveillance Program. PLoS One. 2015;10(10):e0139552.

10. Shi Q, et al. The Characteristics of Chinese Prion Diseases Based On 10 Years Surveillance Data from 2006 To 2015. Neuropsychiatry (London). 2018;8(3):739-44.

11. Shi Q, et al. Analysis of the advantage features of Beijing surveillance network for Creutzfeldt-Jakob disease. Prion. 2015;9(4):304-14.

12. Chen C, et al. Profiles of 14-3-3 and Total Tau in CSF Samples of Chinese Patients of Different Genetic Prion Diseases. Front Neurosci. $2019 ; 13: 934$.

Loading [MathJax]/jax/output/CommonHTML/jax.js 
13. Xiao K, et al. T188K-Familial Creutzfeldt-Jacob Disease, Predominant Among Chinese, has a Reactive Pattern in CSF RT-QulC Different from D178N-Fatal Familial Insomnia and E200K-Familial CJD. Neurosci Bull. 2019;35(3):519-21.

14. Wang GR, et al. Elevated levels of tau protein in cerebrospinal fluid of patients with probable Creutzfeldt-Jakob disease. Am J Med Sci. 2010;340(4):2915 .

15. Eigenbrod S, et al. Comprehensive neuropathologic analysis of genetic prion disease associated with the E196K mutation in PRNP reveals phenotypic heterogeneity. J Neuropathol Exp Neurol. 2011;70(3):192-200.

16. Peoc'h K, et al. Identification of three novel mutations (E196K, V203I, E211Q) in the prion protein gene (PRNP) in inherited prion diseases with CreutzfeldtJakob disease phenotype. Hum Mutat. 2000;15(5):482.

17. Bejot Y, et al. Rare E196K mutation in the PRNP gene of a patient exhibiting behavioral abnormalities. Clin Neurol Neurosurg. 2010;112(3):244-7.

18. Clerici F, et al. Atypical presentation of Creutzfeldt-Jakob disease: the first Italian case associated with E196K mutation in the PRNP gene. J Neurol Sci. 2008;275(1-2):145-7.

19. Tumani $\mathrm{H}$, et al. [Clinically atypical CJD: diagnostic relevance of cerebrospinal fluid markers and molecular genetic analysis?]. Dtsch Med Wochenschr. 2002;127(7):318-20.

20. Chen C, et al. Analyses of the survival time and the influencing factors of chinese patients with prion diseases based on the surveillance data from $2008-$ 2011. PLoS One. 2013;8(5):e62553.

21. Minikel EV, et al. Quantifying prion disease penetrance using large population control cohorts. Sci Transl Med. 2016;8(322):322ra9.

22. Takada LT, et al. Genetic prion disease: Experience of a rapidly progressive dementia center in the United States and a review of the literature. Am J Med Genet B Neuropsychiatr Genet. 2017;174(1):36-69.

23. Spudich S, et al. Complete penetrance of Creutzfeldt-Jakob disease in Libyan Jews carrying the E200K mutation in the prion protein gene. Mol Med. 1995;1(6):607-13.

24. Zhang H, et al. Novel prion protein gene mutation at codon 196 (E196A) in a septuagenarian with Creutzfeldt-Jakob disease. J Clin Neurosci. 2014;21(1):175-8.

25. Unit TNCRS, 27th ANNUAL REPORT 2018, CREUTZFELDT-JAKOB DISEASE SURVEILLANCE IN THE UK.. 2018.

26. Shi Q, et al. Rare genetic Creutzfeldt-Jakob disease with T188K mutation: analysis of clinical, genetic and laboratory features of 30 Chinese patients. J Neurol Neurosurg Psychiatry. 2017;88(10):889-90.

\section{Figures}

A

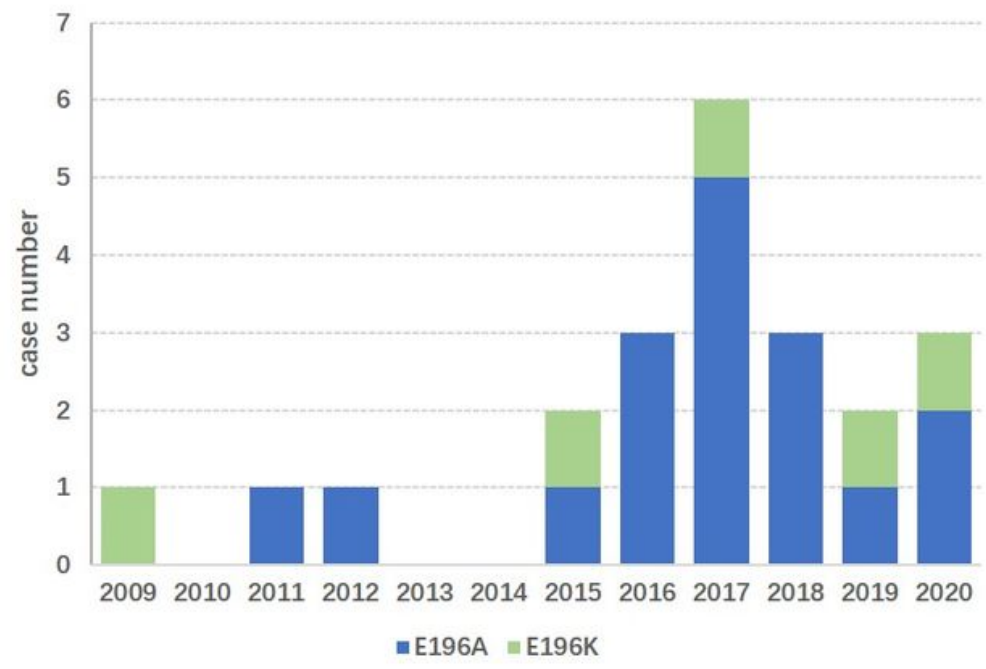

B

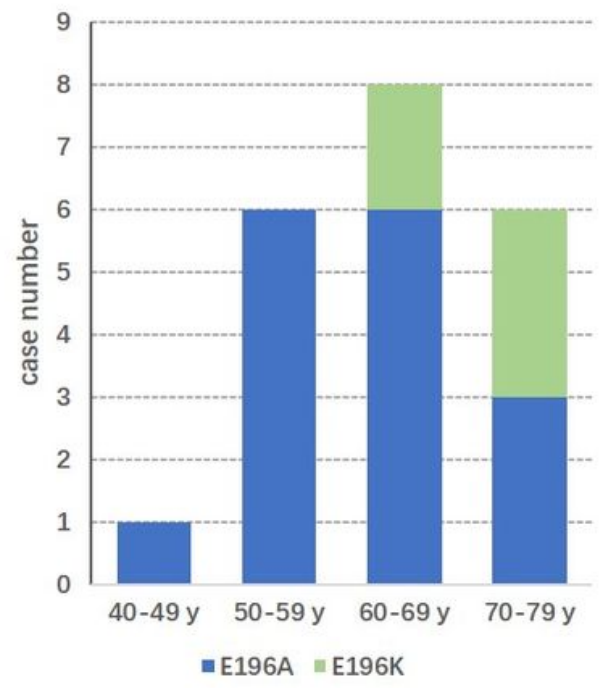

\section{Figure 1}

The distributions of Chinese E196A and E196K gCJD patients based on the diagnosis years (A) and onset-age (B). 
A

\section{E196A}

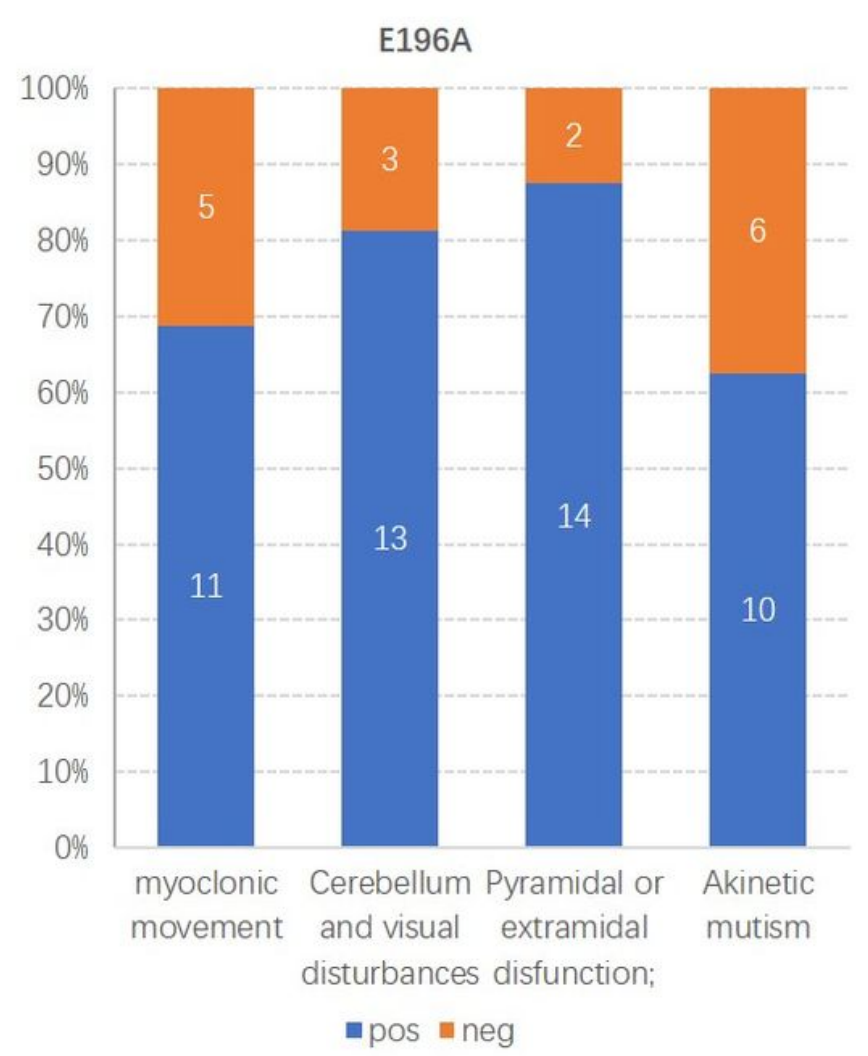

$\because$ pos $\backsim$ neg

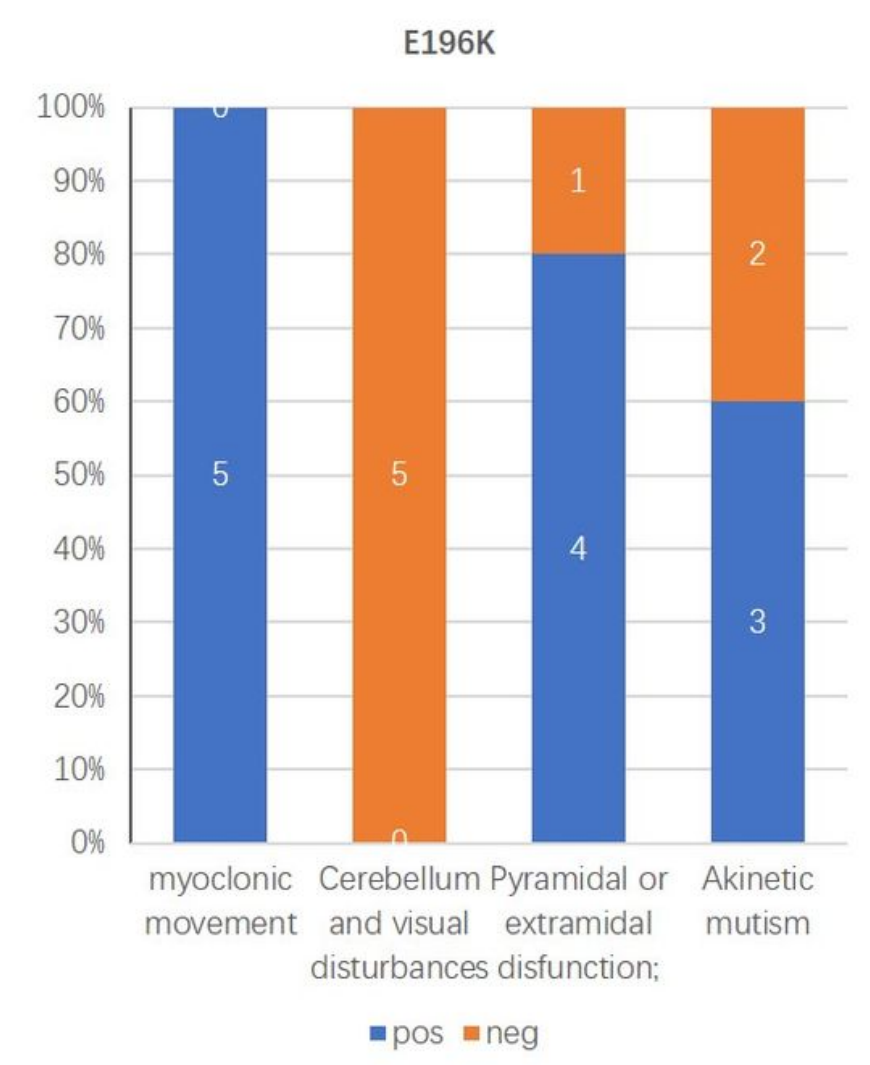

\section{Figure 2}

The positive rates and case numbers of four major sCJD-associated symptoms in Chinese E196A (A) and E196K (B) gCJD patients.

A

EEG

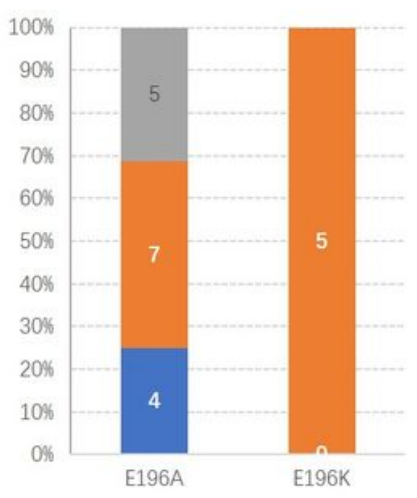

$m$ pos $m$ neg $\equiv \mathrm{NC}$
B

MRI

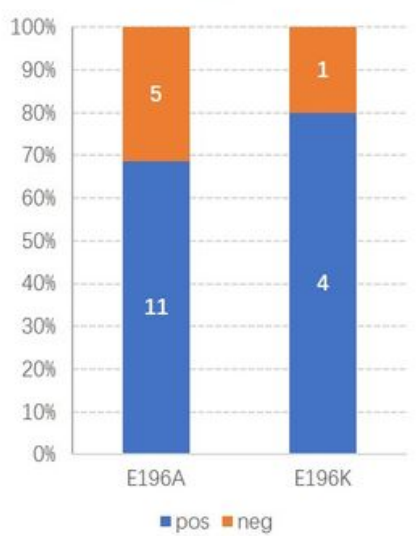

C

CSF $14-3-3$

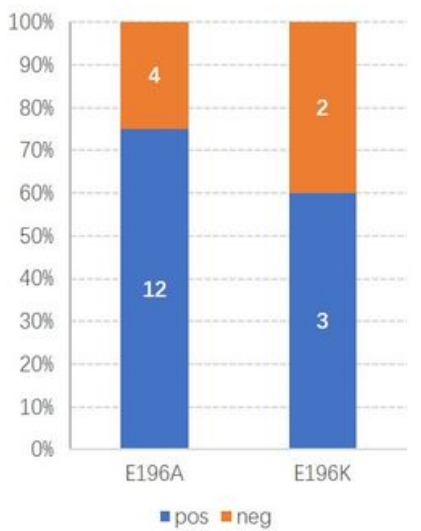

D

tau

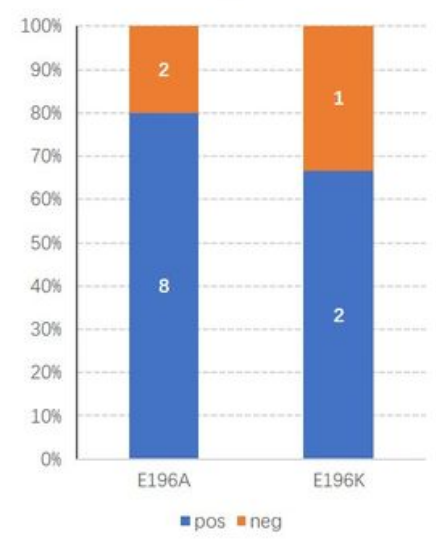

Figure 3

The positive rates and case numbers of various clinical examinations and CSF laboratory tests in Chinese E196A and E196K gCJD patients. A. PSWC on EEG. B. SCJD-associated abnormality on MRI. C. CSF 14-3-3. D. CSF total tau. 
E196A

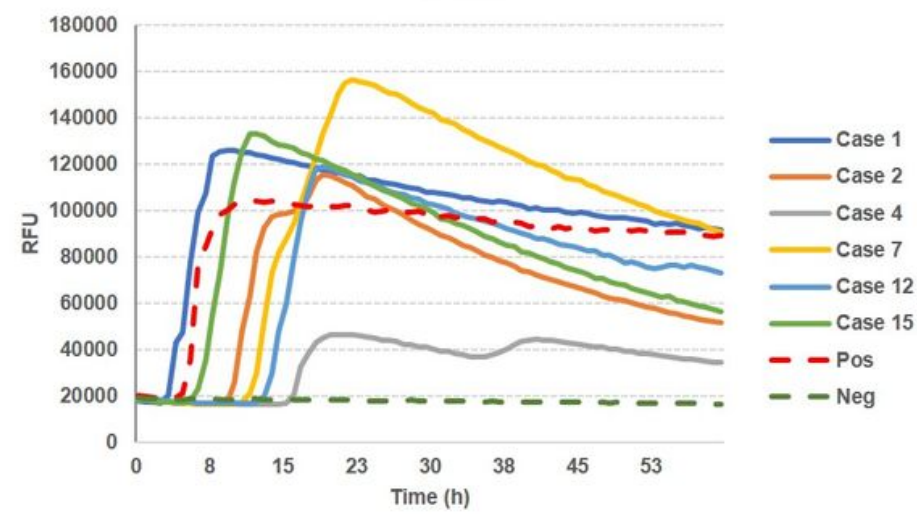

B

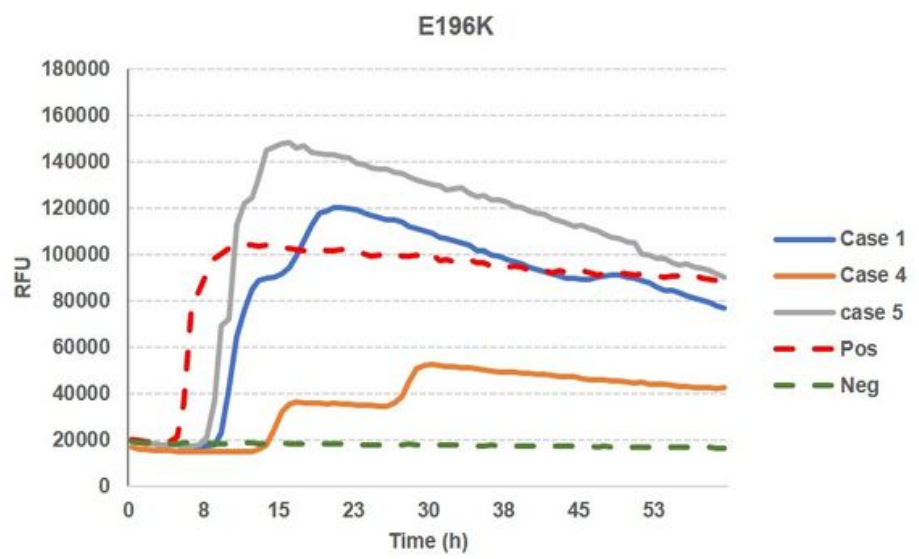

\section{Figure 4}

The positive reactive curves of CSF RT-QuIC of six E196A (A) and three E196K (B) gCJD patients. 10-5 diluted brain homogenate of scrapie agent 263K infected hamster was used as positive control and that of normal hamster was used as negative control. ThT value is showed in $\mathrm{Y}$-axis and hour post-reaction is indicated in X-axis.

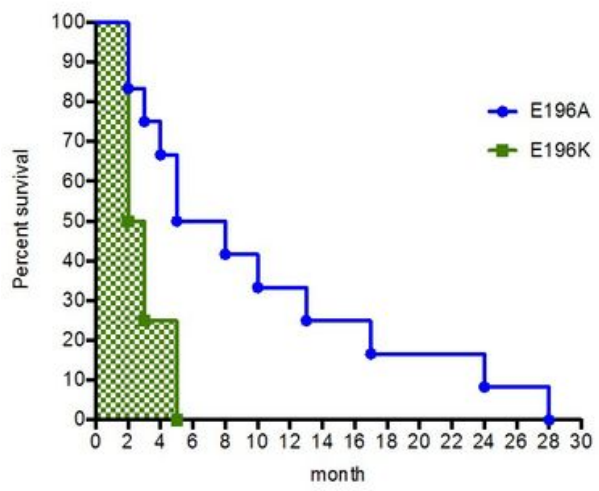

B

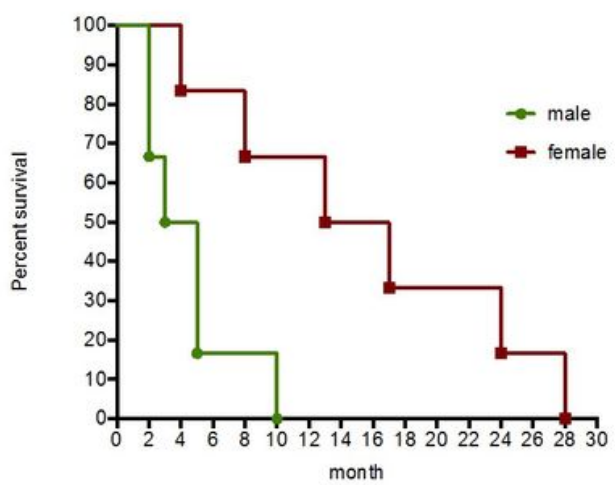

C

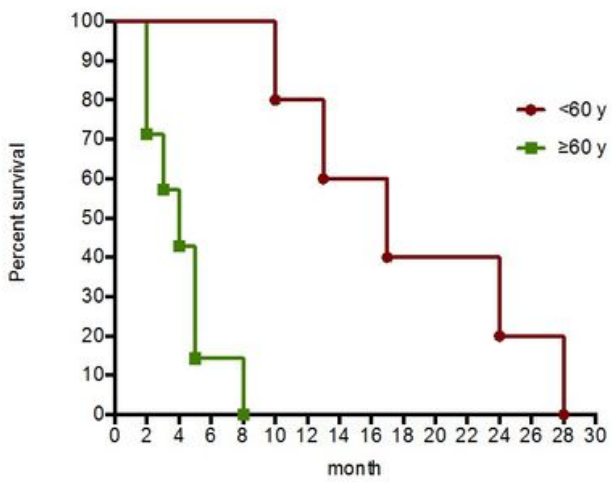

Figure 5

The survival times of Chinese E196A and E196K gCJD patients. A. Survival graph of E196A and E196K gCJD cases. B. Survival graph of E196A cases based on the gender. C. Survival graph of E196A cases based on the onset-age. The survival medians are indicated in the graphs. 